\title{
Crosshatching Incision in Septoplasty: Abandoning an Old Myth
}

\author{
Hong Ryul Jin (ib · Jong-Sook Yi (i) \\ Dr. Jin's Premium Nose Clinic, Seoul, Korea
}

Septoplasty is the most commonly performed surgical procedure in rhinology [1]. Since the introduction of submucosal resection [2], diverse surgical techniques to correct the deviated septum have been developed. In septoplasty, one technique hardly corrects all the diverse deformities of the septum. In 1982, Murakami et al. [3] advocated the crosshatching incisional technique as one maneuver to correct the deviated cartilaginous septum, and it continued to gain popularity until recently. This technique is based on the theory of an internal interlocked stress system of septal cartilage. In their experimental study, Murakami et al. [3] concluded that a full-thickness crosshatching incision on the concave side is the most effective incisional method for straightening the bent cartilage. Yet recently, many surgeons who used this technique have raised questions about the efficacy and safety of this technique due to unintended consequences.

The primary drawbacks of the crosshatching incision are the unpredictability of straightening the curved cartilage and the potential for a weakening of the septum over time. In an issue of Clinical and Experimental Otorhinolaryngology, Kim and Heo [4] compared their experience of crosshatching incision septoplasty with non-incision septoplasty. They reviewed 151 patients who underwent septoplasty using crosshatching incision and 202 patients who did not. All patients were followed up for more than 1 year (mean, 15.9 months). The correction degree of septal deviation and improvement of nasal obstruction were no different between the two groups. Notable complications such as saddle nose deformity and overcorrection after septoplasty were seen in nine patients in the incision group, while the nonincision group lacked any such cases. In the discussion, the authors noted that the biomechanical properties of septal cartilage, scarring during the wound-healing process, and the thickness of septal cartilage may differ widely across individuals, resulting in such outcomes.

In their previous research, the authors performed an experiment with pig ear cartilage to reproduce the original experiment done by Murakami et al. [3] in an actual surgical setting [5]. Unlike Murakami et al.'s study method, the authors fixed two contiguous borders of cartilage with the preservation of a $1 \mathrm{~cm}$ margin like an L-strut, considering the effects of fixation and gravity; they did full-thickness crosshatching incision on the concave side. In this condition, the curvature improvement was found to be only $15.5 \%$. Moreover, newly developed reverse curvatures or splitting of the cartilage occurred. This result is in line with those of Gruber et al. [6] and Min and Chung [7], who warned that the incisional technique could cause instability of the cartilage and scored cartilage could collapse entirely.

In practice, executing the full-thickness crosshatching incision in a regular pattern and at a uniform depth is almost impossible in relatively thin septal cartilage, which most Asians have. From our experience with revision septoplasty, the authors found that a crosshatching incision without proper splinting often fails to correct the curvature of the septum and leads to another deformity [8]. We firmly believe that the curvature of the cartilaginous septum will not be adequately corrected with crosshatching incisions alone, and the additional splinting or battening the weakened cartilage would be an effective way to correct the curvatures.

There is always a rise and fall in the popularity of surgical concepts and techniques. Any new fascinating technique can be discarded if it fails the test of time. The authors think the crosshatching incision technique failed to accumulate relevant evidence of success. Thus, it seems apparent that we are at a point when we should abandon our old myth about the role of this technique in septoplasty.

\section{CONFLICT OF INTEREST}

No potential conflict of interest relevant to this article was reported.

Copyright (C) 2020 by Korean Society of Otorhinolaryngology-Head and Neck Surgery.

This is an open-access article distributed under the terms of the Creative Commons Attribution Non-Commercial License (https://creativecommons.org/licenses/by-nc/4.0)

which permits unrestricted non-commercial use, distribution, and reproduction in any medium, provided the original work is properly cited. 


\section{ORCID}

Hong Ryul Jin https://orcid.org/0000-0001-8887-6792

Jong-Sook Yi https://orcid.org/0000-0003-2798-2326

\section{REFERENCES}

1. Uppal S, Mistry H, Nadig S, Back G, Coatesworth A. Evaluation of patient benefit from nasal septal surgery for nasal obstruction. Auris Nasus Larynx. 2005 Jun;32(2):129-37.

2. Powers GH.Technique of submucous resection of nasal septum. Boston Med Surg J. 1907 May;156:702-4.

3. Murakami WT, Wong LW, Davidson TM. Applications of the biomechanical behavior of cartilage to nasal septoplastic surgery. Laryngoscope. 1982 Mar;92(3):300-9.

4. Kim JS, Heo SJ. Questionable effect of crosshatching incision in sep- toplasty. Clin Exp Otorhinolaryngol. 2020 Feb;13(1):47-51.

5. Heo SJ, Kim JS. Crosshatching incision technique in septoplasty: experimental outcomes under actual surgical settings. Auris Nasus Larynx. 2016 Oct;43(5):518-23.

6. Gruber RP, Nahai F, Bogdan MA, Friedman GD. Changing the convexity and concavity of nasal cartilages and cartilage grafts with horizontal mattress sutures: part II. Clinical results. Plast Reconstr Surg. 2005 Feb;115(2):595-606.

7. Min YG, Chung JW. Cartilaginous incisions in septoplasty. ORL J Otorhinolaryngol Relat Spec. 1996 Jan-Feb;58(1):51-4.

8. Jin HR, Kim DW, Jung HJ. Common sites, etiology, and solutions of persistent septal deviation in revision septoplasty. Clin Exp Otorhinolaryngol. 2018 Dec;11(4):288-92. 